\title{
Feature
}

\section{A 15-Year Study of 63 Teachers at 24 Institutions Reveals: "What the Best College Teachers Do"}

\author{
Review of: What the Best Teachers Do, by Ken Bain; Harvard University Press \\ (Cambridge, MA); ISBN: 0-6740-1325-5
}

\author{
Reviewed by Robin L. Wright, Aaron Charlson, and Carrie F. Olson, College of \\ Biological Sciences, University of Minnesota
}

\section{A PROFESSOR'S VIEW}

In this brief but inspiring book, Ken Bain, director of the Center for Teaching Excellence at New York University, reports results of a 15-year analysis of the scholarship and practices of "the best college teachers in the United States." Although Bain has been interested in understanding the practices of best teachers for more than 40 years, this study was catalyzed by the suicide of Tom Philpott, a gifted teacher whose "library of teaching talents and practices burned to the ground when he died." Bain's motive was to capture and distill the collective wisdom and experience of exceptional college teachers so that their accumulated wisdom did not evaporate when they were lost to us.

The first chapter of the book provides an executive summary of the study and its conclusions. Bain defines the best teachers as those who have a "sustained, substantial, and positive influence on how [their] students think, act, and feel." He briefly describes how he identified a cohort of 63 (mostly) unnamed college teachers who met these criteria, based largely on analysis of student evaluations for evidence of "deep learning." The practices of teachers who made the "best teacher" list, as well as their students, were studied through interviews, statements of their teaching philosophy, observations, analysis of course materials and student work, and comments from colleagues.

In spite of an overall weakness in describing details of how teachers were selected and studied, the conclusions ring true: 1) The best college professors know their subjects extremely well and understand human learning. 2) They prepare to teach with the same rigor and dedication that they bring to their research endeavors. 3) They have high expectations of their students. 4) They create a "natural critical learning environment" in which students confront important problems in ways that force them to rethink assumptions and "examine their mental models of reality." 5) They have deep respect for their students, including an assumption that their students are both able and eager to learn. 6) They assess their own teaching effectiveness and make changes to their approaches based on these data.

DOI: $10.1187 /$ cbe. $05-08-0112$

Address correspondence to: Robin Wright (wrightr@umn.edu).
The remaining chapters of the book elaborate on these conclusions, using many examples from actual classrooms. These examples and anecdotes make the book a great pleasure to read and provide a great deal of its value. In fact, it is one of those books from which I have found new insights and inspiration on my second and third readings. For example, Chapter 2 summarizes our current understanding of human learning, including examples of creative ways in which the best college teachers apply this understanding to their classes. Bain explains the importance of motivating long-term learning through intrinsic rather than extrinsic rewards (usually grades). He then describes ways in which the best college teachers apply this motivating principle in their classes. Among other actions, they avoid assigning grades based on averages of performance throughout the course, provide many and varied opportunities for students to demonstrate mastery, and focus on the subject itself rather than logistical nuts and bolts on the first day of class. Reading this section reinforced my growing discomfort with my own reliance on summative assessment of student learning. Why shouldn't a student who develops a sophisticated understanding of mitosis and meiosis by the end of the course receive the same grade on that subject as a student who gains that understanding earlier in the course? Based on this insight, I now count the final exam grade in lieu of exam averages if it provides students with a higher grade. (Of course, this practice brings up the myriad of problems associated with high-stakes exams and the eternal but unfounded optimism of students that they can always simply ace the next exam. I'm still grappling with these issues.)

The major inadequacy of the book is its minimal description of the teacher selection criteria and methods of analysis. Although more detail is provided in an appendix, the descriptions appear superficial, at least to my sensibilities. In addition, there appear to be no peer-reviewed articles generated by this study to which one could turn for detailed experimental information. In fact, few references of any kind are provided to the reader, and these are confined to a cumbersome "notes" section. The lack of experimental detail is a flaw of the book that creates a deep wound of missed opportunity. For example, on its own, providing a mechanism for using teaching evaluations for more than a popularity poll would have been of great value. Without 
these details, the collective wisdom of this clearly talented and insightful student of great teachers and great teaching runs the risk of being lost in much the same way as the teaching wisdom of Tom Philpott.

Still, in spite of these limitations, this book provided me with useful, practical insights about how I can improve my teaching, even if I never make the best college teacher list. More importantly, it continues to inspire me (now on my fourth reading!) that I can develop more effective ways to support my students' learning, even within the constraints of the limited time I have available to devote to my teaching. This ongoing value has earned What the Best College Teachers Do a special place on my bookshelf.

\section{THE VIEWS OF TWO UNDERGRADUATES ${ }^{1}$}

When we were invited to review What the Best College Teachers Do, we wondered, "How can we, as students, give any insight into what is involved in good teaching?" Surprisingly, we found that this book helped us not only to think more critically about excellent teaching but also to reflect on our own learning. We began to see that our impressions of previous instructors, both good and bad, reflected the criteria the book used to define good teaching. We almost felt inspired to begin writing letters to past teachers either thanking them for taking these factors into account when preparing to enter the classroom or pleading with them to read this book and think about how their own skills could improve by applying these qualities to their lesson plans.

One result of the study that particularly struck us was how Bain selected the best teachers and, consequently, how he defined the best teaching practices. It was a relief to find that the definition of good teaching doesn't just involve how well a particular group of students, usually the upper crust, does on a test. Instead, good teaching involves bringing about inner changes in the student, such as helping students develop a new appreciation of the topic and a desire to pursue it further. It seems too often, at least from our student perspective, that the professor is simply going through the motions to cover the required material without even trying to inspire students to explore beyond the boundaries defined by the expected tests. Our best teachers have had the attitude, emphasized in this book, that it is not sufficient that a student remembers some facts or formulas but that the student learns how to use them. Our experience agrees with the book's definition of what great teaching should encompass: the passion of the professor being passed on to the student.

This definition of good teaching (and learning) runs counter to the emphasis on memorizing facts that we encounter in many of our classes. From our own experience, we know that what we "learned" in such content-focused classes is quickly forgotten after the final examination, creating a "bulimic" learning cycle. The possibility that so much of our hard work in college can be so easily lost is deeply troubling. As described in the book, our best teachers have helped us avoid the learn-purge cycle by taking us beyond the facts and leading us into an understanding of the topic on a deeper, more intuitive level. As the book describes, they have helped us think deeply by asking questions that challenge our preconceived ideas about the subject and point out the flaws or holes in our current understanding. They have taught us in the context of complex or controversial problems. They have torn down everything we thought we knew and helped us replace it with more refined ideas of the world.

We found it very interesting that, as we read this book and thought about best teaching strategies and approaches in general, we also thought about our own learning in ways we hadn't done before. For example, as we evaluated our own best and worst teachers using the principles defined in this book, we began to look for examples of teachers who had had a long-lasting impact on our thinking. Surprisingly, one of these teachers was initially on our "worst teacher" list. Thus, reading about teaching helped us to think more kindly about our professors as well as to examine our own learning in new ways.

The ability of this book to help us reflect on our own learning was particularly valuable. In fact, although we would recommend this book to our faculty who want to improve their teaching, we also would recommend the parts that describe human learning to students. For example, the idea of constructing knowledge rather than receiving it is a message that is important for students and teachers alike. Although teachers play a crucial role in helping their students understand the applications and implications of the information presented, the student must be a willing participant. After all, that's where the learning actually takes place - in the student's brain! Thus, knowing more about how learning happens could help students assess what type of learning strategy they are using and hone their skills to achieve greater learning, no matter what teaching situation they happen to be in.

\footnotetext{
${ }^{1}$ Aaron T. Charlson and Carrie F. Olson are undergraduates at the University of Minnesota. Mr. Charlson is a junior double-majoring in Genetics and Microbiology; Ms. Olson is a junior double-majoring in Genetics and Ecology. Both have been engaged in undergraduate research for several years and share an interest in the undergraduate educational experience, as evidenced by their serving as peer mentors for incoming freshmen. Collectively, they have accumulated more than 8,000 hours in college classes and been taught by approximately 40 different professors. They would like to thank the teachers who have inspired and challenged them; these teachers taught them a great deal about the subject but, more importantly, helped them learn even more about themselves.
} 